\title{
Clinical and neuropathological features associated with loss of RAB39B
}

Yujing Gao, $\mathrm{PhD}^{1,2}$, Verónica Martínez-Cerdeño, $\mathrm{PhD}^{3,4}$, Kirk J. Hogan, MD, JD ${ }^{5,6}$, Catriona A. McLean, MBBS, FRCPA, MD, FFSc (RCPA) ${ }^{7}$, Paul J. Lockhart, PhD ${ }^{1,2 *}$

${ }^{1}$ Bruce Lefroy Centre for Genetic Health Research, Murdoch Children's Research Institute, 50 Flemington Road Parkville, Victoria, 3052, Australia

${ }^{2}$ Department of Pediatrics, The University of Melbourne, 30 Royal Parade Parkville, Victoria, 3052, Australia

${ }^{3}$ Department of Pathology and Laboratory Medicine, UC Davis School of Medicine; Institute for Pediatric Regenerative Medicine and Shriners Hospitals for Children of Northern California ${ }^{4}$ MIND Institute, UC Davis Medical Center

${ }^{5}$ Department of Anesthesiology, University of Wisconsin School of Medicine and Public Health, Madison, WI, USA

${ }^{6}$ Wisconsin Alzheimer's Institute, University of Wisconsin School of Medicine and Public Health, Madison, WI, USA

${ }^{7}$ Anatomical Pathology, Alfred Hospital, Melbourne Victoria 3004 Australia

*Corresponding author: Associate Professor Paul J. Lockhart, Murdoch Children's Research Institute, 50 Flemington Road Parkville, Victoria, 3052, Australia. Phone: +61 (3) 8341-6322.

Email: paul.lockhart@mcri.edu.au

This is the author manuscript accepted for publication and has undergone full peer review but has not been through the copyediting, typesetting, pagination and proofreading process, which may lead to differences between this version and the Version of Record. Please cite this article as doi: $10.1002 / \mathrm{mds} .27951$

This article is protected by copyright. All rights reserved. 
Word count: 2250

Running title: Loss of RAB39B in PD

Keywords: RAB39B, Parkinsonism, Parkinson's disease, Parkinson's disease dementia, neuropathology.

Financial disclosure/conflicts of interest: Nothing to report.

Funding sources for study: This work was funded in part by the McCusker Charitable Foundation, National Health \& Medical Research Council (Australia) project grants (GNT1041860, GNT1144724) and the Michael J Fox Foundation/Shake It Up Grant (12173) to P.J.L. Additional infrastructure funding to the Murdoch Children's Research Institute was provided by the Australian Government National Health and Medical Research Council Independent Research Institute Infrastructure Support Scheme and the Victorian Government's Operational Infrastructure Support Program. P.J.L is supported by the Vincent Chiodo Foundation. The Victorian Brain Bank is supported by The Florey Institute of Neuroscience and Mental Health, The Alfred Hospital and the Victorian Institute of Forensic Medicine, and funded in part by Parkinson's Victoria, Motor Neurone Disease Victoria and Cure for Motor Neurone Disease Foundation. The UC Davis tissue repository is supported by

This article is protected by copyright. All rights reserved. 
National Institutes of Health grants (GM113929, HD036071, and R011NS107131). The funding bodies had no role in the design, analysis, interpretation or reporting of results.

This article is protected by copyright. All rights reserved. 


\begin{abstract}
Background: Pathogenic variants in the small GTPase Ras analogue in Brain 39b (RAB39B) have been linked to the development of early-onset parkinsonism.
\end{abstract}

Objectives: This study aimed to delineate the clinical and neuropathological features associated with a previously reported pathogenic variant in $R A B 39 B$ (c.503C >A p.T168K), and test for dysregulation of RAB39B in idiopathic PD.

Methods and Results: Clinical details of a male individual hemizygous for the T168K variant were collected by systematic review of medical records. Neuropathological examination showed extensive dopaminergic neuron loss, widespread Lewy pathology and iron accumulation in the substantia nigra. Additional pathology was observed in the hippocampus and thalamus. Western blot analysis demonstrated the T168K variant results in loss of RAB39B. In individuals with idiopathic PD $(n=10,6 M / 4 F)$, steady-state RAB39B was significantly reduced in the prefrontal cortex and substantia nigra.

Conclusions: T168K RAB39B is unstable in vivo and associated with dopaminergic neuron loss and Lewy pathology. Dysregulation of RAB39B in the prefrontal cortex and substantia nigra of individuals with idiopathic PD potentially implicates the protein more broadly in the pathological mechanisms underlying PD and related Lewy body disorders.

This article is protected by copyright. All rights reserved. 


\section{Introduction}

Parkinson's disease (PD) is a common neurodegenerative disorder that manifests with motor symptoms including resting tremor, rigidity, bradykinesia, shuffling gait and postural instability ${ }^{1}$. These motor deficits are mediated by the hallmark neuropathological features of $\mathrm{PD}$, including loss of dopaminergic neurons in the substantia nigra (SN) and presence of intraneuronal $\alpha$-synuclein ( $\alpha \mathrm{SN}$ ) positive inclusions termed Lewy bodies ${ }^{2}$. Additional nonmotor features may also develop, including a range of sleep, neuropsychiatric and sensory disturbances ${ }^{1}$.

Currently, the majority of PD cases are of unknown aetiology (idiopathic), although causal variants in greater than 20 genes have been found to underlie $\sim 10-15 \%$ of cases ${ }^{2,3}$. PD is responsive to symptomatic treatment with levodopa, whereas parkinsonism is a general term to describe disorders similar to PD that do not respond or respond only for a short time to levodopa therapy. Recently, loss of function variants in a small GTPase involved with intracellular trafficking in the CNS, Ras Analogue in Brain 39b (RAB39B), were linked to the development of X-linked recessive early-onset parkinsonism with non-progressive intellectual disability (ID) and macrocephaly ${ }^{4}$. Subsequent studies confirmed the role of $R A B 39 B$ in PD, although the results of several cohort screens suggest pathogenic variants are a rare cause of PD ${ }^{5-12}$. One report demonstrated that the pathogenic variant G192R caused clinically typical PD independent of intellectual disability ${ }^{6}$. The neuropathological features of $R A B 39 B-$ mediated parkinsonism have only been described in one case to date, an affected individual

This article is protected by copyright. All rights reserved. 
with deletion of the entire $R A B 39 B$ locus. This revealed the hallmark pathological features of PD in the SN, including loss of dopaminergic neurons and the presence of $\alpha \mathrm{SN}$ positive Lewy bodies and Lewy neurites in surviving neurons. Additional disease features included cortical Lewy bodies, and Tau positive neurofibrillary tangles (NFT) and modest iron accumulation in the $\mathrm{SN}^{4}$. Here, we describe the clinical features and neuropathology of an individual from a large pedigree carrying the pathogenic RAB39B T168K variant (NM_171998.3: c.503C>A p.T168K). Our results showed a consistent neuropathology associated with $R A B 39 B$-mediated parkinsonism. In addition, we examined steady state RAB39B in brain tissue from individuals with idiopathic PD (iPD) and showed that RAB39B is dysregulated in the prefrontal cortex and SN in iPD. These results potentially implicate RAB39B more broadly in the pathological mechanisms underlying iPD and warrant further investigation.

This article is protected by copyright. All rights reserved. 


\section{Materials and Methods}

\section{Human brain tissue}

The Royal Children's Hospital Human Research Ethics Committee approved the study (HREC 28097). Brain tissues from individuals with pathologically-proven iPD were received from the Victorian Brain Bank (Melbourne, Australia) and the University of California FXTAS/FXS tissue repository (Davis, USA). Operation of the Victorian Brain Bank, including consent and ethical approval, is under the jurisdiction of the Human Research Ethics Committee of the University of Melbourne and the Victorian Institute of Forensic Medicine.

\section{Post mortem neuropathology}

Neuropathological studies were performed as previously described ${ }^{4}$. Briefly, we utilized routine haematoxylin and eosin (H\&E) stained tissue sections. To detect PD associated proteins, immunohistochemistry (IHC) was performed on $5 \mu \mathrm{m}$ formalin fixed paraffin embedded tissue sections. Sections were deparaffinized and sequentially treated with $80 \%$ formic acid for five minutes to achieve antigen retrieval, and $3 \%$ hydrogen peroxide to eliminate endogenous peroxidase activity. Subsequently, sections were incubated with blocking buffer (20\% foetal calf serum, $50 \mathrm{mM}$ Tris- $\mathrm{HCl}$, and $175 \mathrm{mM} \mathrm{NaCl} \mathrm{pH} \mathrm{7.4),} \mathrm{then}$ primary antibodies (rabbit anti- $\alpha \mathrm{SN}{ }^{13}$ and rabbit anti-Tau (Dako, A0024)). Primary antibodies were detected with the LSABTM kit (Dako) and immunoreactivity visualised with hydrogen peroxidase diaminobenzidine $\left(\mathrm{H}_{2} \mathrm{O}_{2}-\mathrm{DAB}\right)$. Non-haem iron $\left(\mathrm{Fe}^{2+}\right.$ and $\left.\mathrm{Fe}^{3+}\right)$ was detected by Perl's stain as previously described ${ }^{4}$.

This article is protected by copyright. All rights reserved. 


\section{Cell culture and transfection}

BE(2)-M17 human neuroblastoma cells were maintained in Opti-MEM (Invitrogen) supplemented with 10\% FBS. Cells were transfected with RAB39B wildtype or T168K mammalian expression constructs (pcDNA3.1, Invitrogen) using FugeneHD (Roche), and selected with $400 \mu \mathrm{g} / \mathrm{ml}$ Geneticin.

\section{Protein extraction and western blotting}

Western blot analysis was performed as previously described ${ }^{14}$. Briefly, total protein was extracted using buffer containing $2 \%$ SDS and $1 x$ Protease inhibitor (Sigma). Twenty micrograms of total protein was separated on $12 \%$ SDS-PAGE and transferred onto $0.45 \mu \mathrm{m}$ pore PVDF membranes (Immobilon-P) at 10V overnight. Membranes were blocked in 5\% skim milk for two hours, then incubated with primary antibodies (rabbit anti-RAB39B (Proteintech, 12162-1-AP) and mouse anti- $\beta$-Actin (Sigma, A5441)). Antibody binding was revealed using horseradish peroxidase-conjugated secondary antibodies (Jackson Laboratories) and enhanced chemiluminescence (ECL) (Bio-Rad). Images were captured with ImageQuant LAS4000 and quantified using ImageQuantTL software (GE Healthcare). To quantify RAB39B steady state levels, the signal intensity was normalized to the loading control $\beta$-Actin, and control groups were assigned a relative value of 1 . Samples were analyzed by tissue group, with simultaneous antibody incubation and imaging to enable direct comparison of steadystate levels between control and case samples from the same brain region.

This article is protected by copyright. All rights reserved. 


\section{Statistical analysis}

Statistical significance was determined using unpaired student t-tests (Graphpad Prism 7, CA, USA). All quantified data are displayed as mean $+/-$ standard error of the mean (SEM).

This article is protected by copyright. All rights reserved. 


\section{Results}

Clinical features associated with RAB39B T168K

We collected and reviewed all available clinical data for individual IV:12 from the previously described Wisconsin kindred carrying the $R A B 39 B$ T168K mutation (Figure $1 A$ ) ${ }^{4}$. Individual IV:12 shared with his brothers a syndrome comprising megalocephaly, non-progressive ID and early-onset parkinsonism ${ }^{4,15}$. He developed motor seizures at two years of age and was responsive to therapy. At age nine he was noted to have "very inadequate" hand and eye coordination, elective mutism, megalocephaly and an IQ of 69. Evaluation at age 17 showed severe incoordination, and social and mental handicaps with an IQ of 53, albeit with a surprisingly high level of reading and comprehension. Anticonvulsant dependent epileptogenic activity was observed on his EEG, a larger than normal cranial vault was seen on skull X-ray without evidence of calcification, and contemporary blood and urine metabolic screening tests were within normal limits. At age 19 his finger dexterity appeared to be in "slow motion", with a mild intention tremor and shuffling gait. Repeat metabolic tests were normal. At age 21 his gait was halting, with truncal ataxia and persistent mutism. His EEG revealed diffuse encephalopathy with active cortical-reticular discharges, and diffuse slow wave abnormalities. A mild tremor on intent was noted at age 28 , with arms carried at a high angle but with no cogwheel rigidity. Examination at 30 years of age demonstrated mild cogwheel rigidity, a Parkinsonian posture and gait, facial hypominima, and a resting hand tremor. The remainder of his neurologic exam was normal. A trial of carbidopa and levodopa (Sinemet) was abandoned for lack of benefit. At age 31 his clinical signs and symptoms were

This article is protected by copyright. All rights reserved. 
unchanged. Subsequent clinical records were unavailable for review, and the patient died at 53 from undetermined causes.

\section{Neuropathological features associated with RAB39B T168K}

Fresh frozen and fixed tissue was available from the prefrontal cortex, hippocampus, SN, putamen and thalamus from individual IV:12. Western blot analysis demonstrated significantly reduced steady-state levels of T168K RAB39B compared to the substantial levels in equivalent brain regions of healthy aged controls (Figure 1B). This outcome is consistent with in vitro overexpression models, which show significantly reduced levels of T168K compared to wildtype RAB39B (Figure 1B), due to ubiquitin-proteasome mediated turnover of the unstable protein ${ }^{4}$. Collectively, these in vivo results are consistent with previous in silico and in vitro results indicating a loss of function mechanism associated with the development of RAB39B-mediated parkinsonism ${ }^{4}$. Neuropathological examination of the SN revealed $\alpha \mathrm{SN}$ positive Lewy bodies and neurites (Figure 1C, D), substantial neuronal loss, pigment incontinence and modest levels of intraneuronal iron deposition (Figure 1E). We observed neuropathological features in two additional regions. In the thalamus, we observed minor neuronal loss and occasional $\alpha \mathrm{SN}$ positive Lewy-like bodies (Figure 1F), along with Tau positive NFTs (Figure 1G). In the hippocampus, we identified mild neuronal loss and $\alpha$ SN positive Lewy bodies and neurites in the pyramidal layers (Figure 1I), and spongy change associated with scant $\alpha \mathrm{SN}$ positive Lewy bodies in the CA4 region (Figure $1 \mathrm{~J}$ ). There was no obvious 
neuropathology or iron accumulation observed in the prefrontal cortex or putamen (Figure $1 \mathrm{H}, \mathrm{K})$.

\section{Steady state RAB39B is dysregulated in IPD}

We obtained fresh frozen brain tissue from ten late-onset iPD cases, and ten age and gender matched controls from the Victorian Brain Bank (sex ratio 1.5 male/female, age $79.5 \pm 5.0$ years, post mortem interval (PMI) $38.3 \pm 16.9$ hours). Six of the iPD cases had developed iPD with dementia (iPD-PDD), as defined by the onset of cognitive decline greater than 12 months after the onset of iPD ${ }^{16}$. Regions that were available for analysis included the cortex (dorsomedial prefrontal region), hippocampus (CA1 region and dentate gyrus), SN (pars compacta and reticulata), caudate nucleus and thalamus (dorsomedial thalamic nucleus). By western blot analysis, we observed $\sim 70 \%$ reduction of steady state RAB39B in iPD tissue in the cortex (PD: $0.29 \pm 0.04, n=10, p=0.0001$ ) (Figure $2 A, B$ ) and SN (PD: $0.31 \pm 0.08, n=10, p=0.0004$ ) (Figure $2 \mathrm{l}, \mathrm{J}$ ) compared to healthy controls. In contrast, we did not observe any significant differences in the hippocampus (Figure 2C, D), thalamus (Figure 2E, F) or caudate nucleus (Figure 2G, H). We further investigated RAB39B levels in iPD cases stratified by the presence of dementia. Although there was no statistically significant difference, we observed a trend towards greater reduction of RAB39B in PD with dementia (PDD) cases compared to cases with no dementia (No PDD) in the cortex (No PDD: $0.37 \pm 0.05, n=4$ vs PDD: $0.23 \pm 0.04, n=6$ $(p=0.066)$ ) (Figure $2 A, B$ ) and hippocampus (No PDD: $1.05 \pm 0.15, n=4$ vs PDD: $0.75 \pm 0.07, n=6$ $(p=0.073))$ (Figure 2C, D). 


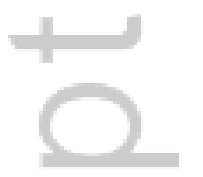

This article is protected by copyright. All rights reserved. 


\section{Discussion}

$R A B 39 B$ is a novel PD associated gene encoding a protein with a putative function in intracellular trafficking in the CNS. Currently, little is known about the role of $R A B 39 B$ in PD and there are a limited number of cases reported. In this study, we confirmed loss of RAB39B in vivo in an individual carrying the $R A B 39 B$ T168K variant. We identified clinical and neuropathological features that are commonly associated with PD and comparable with $R A B 39 B$ deletion. This is the second neuropathological assessment performed for $R A B 39 B-$ mediated parkinsonism with the pathogenic mechanism being loss of function due to two independent mutation mechanisms, gene deletion and protein instability secondary to a missense variant, respectively. Collectively, the neuropathology associated with this genetic form of parkinsonism is characterized by the typical features of PD including neuronal loss, Lewy pathology and iron accumulation in the SN.

We observed additional neuropathological features, some of which were differential between the two case reports. In particular, we observed Tau pathology in the SN and abundant cortical Lewy bodies only in the case with the RAB39B deletion. We also observed Tau pathology in the thalamus and Lewy pathology in the thalamus and hippocampus with RAB39B T168K, however we were unable to assess these regions in the $R A B 39 B$ deletion case. Tau pathology has previously been identified in $\mathrm{PPD}^{17}$ and other genetic forms of PD (SNCA, PARKIN, LRRK2, DJ1) ${ }^{18}$. Further, Tau and $\alpha \mathrm{SN}$ positive inclusions can co-occur in other parkinsonisms and neurodegenerative disorders ${ }^{17}$, although the functional interplay between the two proteins 
are largely unknown. Similarly, pathology in cortical regions are common during the later stages of PD progression, and has also been identified in familial forms of PD (SNCA, PINK1, DJ1, LRRK2, PLA2G6) ${ }^{18}$. Both cortical and hippocampal pathology may correlate with cognitive decline in PD ${ }^{19,20}$. Indeed, in $R A B 39 B$-mediated parkinsonism, the presence of pathology in these regions is consistent with the development of cognitive dysfunction in the disorder. Further cases of $R A B 39 B$-mediated parkinsonism will need to be assessed in order to better define the full phenotypic spectrum of the disorder, and help guide differential diagnosis from other parkinsonian disorders.

We also investigated a potential role for RAB39B in iPD. Interestingly, we observed significantly reduced steady state levels of RAB39B in the SN and prefrontal cortex but not the hippocampus, caudate nucleus, or thalamus of individuals with iPD. Decreased levels of RAB39B in the $S N$ is expected given the substantial neuronal loss typically observed in this region. However, it is unclear how and why RAB39B is reduced in the prefrontal cortex. Potentially, this is associated with the function(s) of RAB39B in cognition ${ }^{21-24}$ and the manifestation of cortical abnormalities in iPD. For example, cortical thinning, reduced grey matter volume, reduced cortical gyrification and altered cortical microstructure have been previously reported in iPD ${ }^{25-29}$. A proportion of individuals in our iPD cohort had developed dementia following diagnosis of PD. Given that the prefrontal cortex and hippocampus play critical roles in cognition ${ }^{30}$, we determined the reduction in RAB39B levels in these regions of individuals with dementia compared to no dementia. We identified a trend towards greater reduction of RAB39B in PDD compared to no PDD in both regions. However, perhaps due to 
the small sample size available, these trends did not achieve statistical significance. Given this caveat, and the potential limits of quantitative western blotting to accurately determine small differences in target protein abundance, it will be of interest to replicate these studies in larger cohorts, as well as in other dementia syndromes such as dementia with Lewy bodies, to test the potential role of RAB39B in dementia and delineate the mechanisms underlying cognitive dysfunction in $R A B 39 B$-mediated disease.

Overall, our study implicated RAB39B in the development of a rare genetic form of parkinsonism, mediated by loss of RAB39B, and potentially more broadly in the development of iPD, mediated by altered homeostasis of steady state RAB39B. Our results highlight the significance of dysregulated intracellular trafficking in the pathological mechanisms underlying both genetic and $\mathrm{PPD}$. The potential role of RAB39B in iPD warrants further investigation, with implications for improved understanding of the pathomechanisms mediating PD and associated Lewy body disorders.

This article is protected by copyright. All rights reserved. 


\section{Authors' contributions}

1) Research project: A. Conception, B. Organization, C. Execution; 2) Statistical Analysis: A. Design, B. Execution, C. Review and Critique; 3) Manuscript: A. Writing of the first draft, B. Review and Critique.

Y.G.: 1A, 1B, 1C, 2A, 2B, 3A

V.M-C: 1C, 2C, 3B

K.J.H: 1C, 2C, 3B

C.A.M: 1B, 2C, 3B

P.J.L: 1A, 1B, 2A, 3A, 3B

\section{Financial Disclosures}

Y.G: None

V.M-C: None

K.J.H: NIH 1 RO1AG027161-01A2, Wisconsin Registry for Alzheimer's disease Prevention (WRAP): Biomarkers of Preclinical AD (2018-2022); NIH 1 UF1 AG051216-01A1, Human Aging Connectome Project (2015-2020); NIH RO1AG054047, Genomic and Metabolomic Data Integration in a Longitudinal Cohort at Risk for Alzheimer's disease (2016-2021).

C.A.M.: None

P.J.L: NHMRC Australia, GNT1128933, Understanding RAB39B-mediated Parkinson's disease (2018-2020); NHMRC Australia, GNT1128933, Tuberous sclerosis and epilepsy: using resected tissue to understand pathogenesis and inform management (2017-2018); NHMRC Australia,

This article is protected by copyright. All rights reserved. 
GNT1098255, Understanding the Neurobiology of Autism Spectrum Disorder (2016-2020); NHMRC Australia, GNT102207, A randomized placebo-controlled crossover trial of micronized resveratrol as a treatment for Friedreich ataxia (2016-2018)

This article is protected by copyright. All rights reserved. 


\section{Figure legends}

\section{Figure 1: Neuropathology associated with RAB39B T168K}

(A) Simplified pedigree of the Wisconsin kindred (individual IV:12 indicated) ${ }^{4}$. (B) Western blot analysis of RAB39B in brain tissue from individual IV:12 compared to a healthy control, and of RAB39B in $\mathrm{BE}(2)-\mathrm{M} 17$ neuroblastoma cells overexpressing wildtype or T168K RAB39B. (C-K) Microscopic examination of neuropathology in brain tissue from individual IV:12. Examination of SN showed (C) intracellular Lewy bodies (H\&E), (D) aSN positive Lewy bodies and neurites (IHC), (E) neuronal loss, pigment incontinence (H\&E) and iron deposition (Perl's stain). Examination of thalamus showed (F) neuronal loss and $\alpha \mathrm{SN}$ positive Lewy-like bodies and (G) Tau positive NFTs (IHC). Examination of hippocampus showed (I) neuronal loss and $\alpha \mathrm{SN}$ positive Lewy bodies and neurites in pyramidal layers and $(\mathrm{J}) \alpha \mathrm{SN}$ positive Lewy bodies in the CA4 region (IHC). No obvious neuropathology was observed in the $(\mathrm{H})$ putamen or $(\mathrm{K})$ prefrontal cortex (H\&E). Scale bar $=20 \mu \mathrm{m}(C D, F, G, I, J)$ or $50 \mu m(E, H, K)$.

\section{Figure 2: Distribution of RAB39B in iPD}

Western blot analysis and quantification of steady state RAB39B normalized to $\beta$-Actin in the (A, B) prefrontal cortex, (C, D) hippocampus, (E, F) thalamus, (G, H) caudate nucleus, and (I, J) SN of individuals with iPD (with or without dementia), no PDD (iPD without dementia) or PDD (iPD with dementia) compared to healthy controls (mean $\pm S E M, n=10$ controls ( $n=8$ for $S N$ ), $\mathrm{n}=10$ iPD; $* \mathrm{p}<0.05, * * \mathrm{p}<0.005, * * * \mathrm{p}<0.0005)$. 


\section{References}

1. Sveinbjornsdottir S. The clinical symptoms of Parkinson's disease. J Neurochem 2016;139(S1):318-324.

2. Poewe W, Seppi K, Tanner CM, et al. Parkinson disease. Nat Rev Dis Primers 2017;3:17013.

3. Hernandez DG, Reed X, Singleton AB. Genetics in Parkinson disease: Mendelian versus non-Mendelian inheritance. J Neurochem 2016;139(S1):59-74.

4. Wilson GR, Sim JC, McLean C, et al. Mutations in RAB39B cause X-linked intellectual disability and early-onset Parkinson disease with $\alpha$-synuclein pathology. Am J Hum Genet 2014;95(6):729-735.

5. Lesage S, Bras J, Cormier-Dequaire F, et al. Loss-of-function mutations in RAB39B are associated with typical early-onset Parkinson disease. Neurol Genet 2015;1(1):e9.

6. Mata IF, Jang Y, Kim C-HH, et al. The RAB39B p.G192R mutation causes X-linked dominant Parkinson's disease. Mol Neurodegener 2015;10:50.

7. Yuan L, Deng X, Song Z, et al. Genetic analysis of the RAB39B gene in Chinese Han patients with Parkinson's disease. Neurobiol Aging 2015;36(10):2907.e2911-2902.

8. Hodges $\mathrm{K}$, Brewer SS, Labbé $\mathrm{C}$, et al. RAB39B gene mutations are not a common cause of Parkinson's disease or dementia with Lewy bodies. Neurobiol Aging 2016;45:107108.

9. Kang J-FF, Luo Y, Tang B-SS, et al. RAB39B gene mutations are not linked to familial Parkinson's disease in China. Sci Rep 2016;6:34502.

This article is protected by copyright. All rights reserved. 
10. Liu Z, Tang B, Guo J, et al. Mutations analysis of RAB39B gene in Chinese early-onset Parkinson's disease. Parkinsonism Relat Disord 2016;28:157-158.

11. Löchte T, Brüggemann N, Vollstedt E-JJ, et al. RAB39B mutations are a rare finding in Parkinson disease patients. Parkinsonism Relat Disord 2016;23:116-117.

12. Shi C-HH, Zhang S-YY, Yang Z-HH, et al. A novel RAB39B gene mutation in X-linked juvenile parkinsonism with basal ganglia calcification. Mov Disord 2016;31(12):1905-1909.

13. Culvenor JG, McLean CA, Cutt S, et al. Non-Abeta component of Alzheimer's disease amyloid (NAC) revisited. NAC and alpha-synuclein are not associated with Abeta amyloid. Am J Pathol 1999;155(4):1173-1181.

14. Stephenson SEM, Aumann TD, Taylor JM, et al. Generation and characterisation of a parkin-Pacrg knockout mouse line and a Pacrg knockout mouse line. Sci Rep 2018;8(1):7528. 15. Laxova R, Brown ES, Hogan K, Hecox K, Opitz JM. An X-linked recessive basal ganglia disorder with mental retardation. Am J Med Genet 1985;21(4):681-689.

16. McKeith IG, Dickson DW, Lowe J, et al. Diagnosis and management of dementia with Lewy bodies: third report of the DLB Consortium. Neurology 2005;65(12):1863-1872.

17. Wray S, Lewis PA. A tangled web - tau and sporadic Parkinson's disease. Frontiers in psychiatry 2010;1:150.

18. Schneider SA, Alcalay RN. Neuropathology of genetic synucleinopathies with parkinsonism: Review of the literature. Mov Disord 2017;32(11):1504-1523.

19. Camicioli R, Moore MM, Kinney A, Corbridge E, Glassberg K, Kaye JA. Parkinson's disease is associated with hippocampal atrophy. Mov Disord 2003;18(7):784-790. 
20. Mattila PM, Röyttä M, Torikka H, Dickson DW, Rinne JO. Cortical Lewy bodies and Alzheimer-type changes in patients with Parkinson's disease. Acta neuropathol 1998;95(6):576-582.

21. Giannandrea M, Bianchi V, Mignogna ML, et al. Mutations in the small GTPase gene RAB39B are responsible for $\mathrm{X}$-linked mental retardation associated with autism, epilepsy, and macrocephaly. Am J Hum Genet 2010;86(2):185-195.

22. Mignogna $M L$, Giannandrea $M$, Gurgone $A$, et al. The intellectual disability protein RAB39B selectively regulates GluA2 trafficking to determine synaptic AMPAR composition. Nat Commun 2015;6:6504.

23. Vanmarsenille L, Giannandrea M, Fieremans N, et al. Increased dosage of RAB39B affects neuronal development and could explain the cognitive impairment in male patients with distal Xq28 copy number gains. Hum Mutat 2014;35(3):377-383.

24. Woodbury-Smith M, Deneault E, Yuen RKC, et al. Mutations in RAB39B in individuals with intellectual disability, autism spectrum disorder, and macrocephaly. Mol Autism 2017;8:59.

25. Mak E, Su L, Williams GB, et al. Baseline and longitudinal grey matter changes in newly diagnosed Parkinson's disease: ICICLE-PD study. Brain 2015;138(Pt 10):2974-2986. 26. Jia X, Liang P, Li Y, Shi L, Wang D, Li K. Longitudinal Study of Gray Matter Changes in Parkinson Disease. AJNR Am J Neuroradiol 2015;36(12):2219-2226.

27. Sterling NW, Wang M, Zhang L, et al. Stage-dependent loss of cortical gyrification as Parkinson disease "unfolds". Neurology 2016;86(12):1143-1151. 
28. Vymazal J, Righini A, Brooks RA, et al. T1 and T2 in the brain of healthy subjects, patients with Parkinson disease, and patients with multiple system atrophy: relation to iron content. Radiology 1999;211(2):489-495.

29. Nurnberger L, Gracien RM, Hok P, et al. Longitudinal changes of cortical microstructure in Parkinson's disease assessed with T1 relaxometry. Neuroimage Clin 2017;13:405-414.

30. Miller EK. The prefrontal cortex and cognitive control. Nat Rev Neurosci 2000;1(1):5965.

This article is protected by copyright. All rights reserved. 


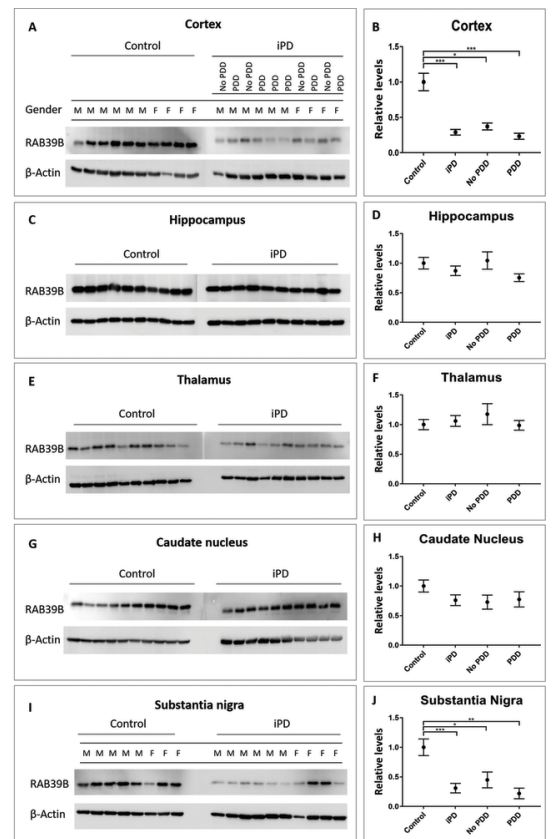

MDS_27951_Figure2 600dpi.tif

This article is protected by copyright. All rights reserved. 


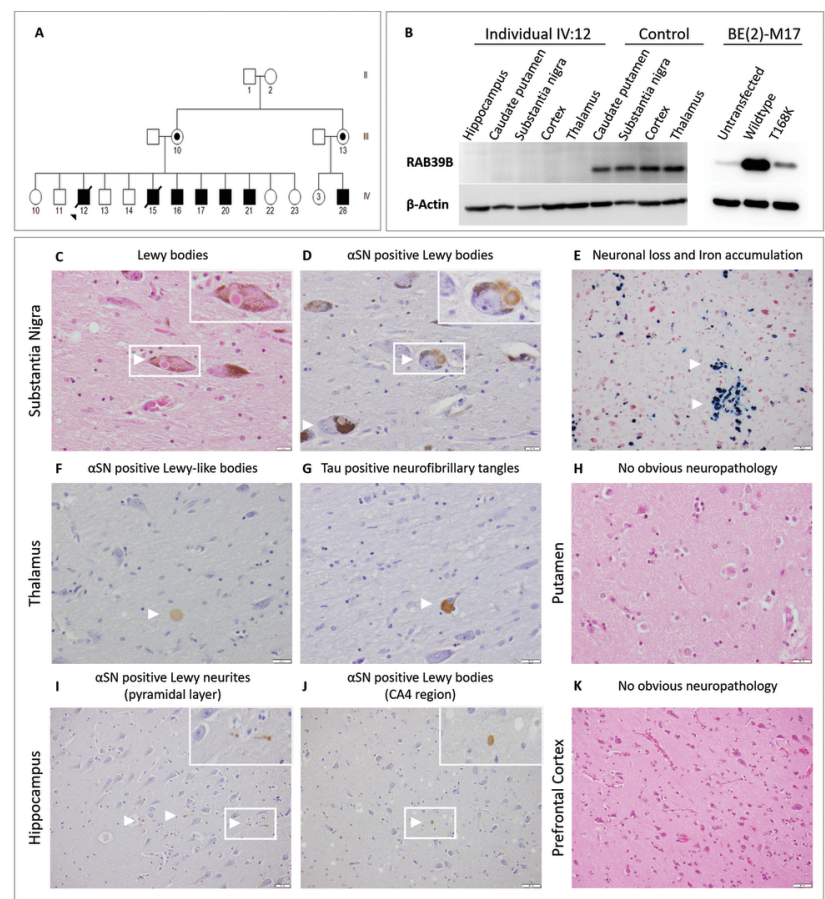

MDS_27951_Figure 1 600DPI.tif

This article is protected by copyright. All rights reserved. 


\section{COPYRIGHT TRANSFER AGREEMENT}

Date: 11th November 2019

Contributor name: Paul Lockhart

Contributor address: MCRI, 50 Flemington Rd, Parkville, Australia, 3052

Manuscript number: MDS19-1125

Re: Manuscript entitled: Clinical and neuropathological featurestassogiatedimith loss of RAB39B

for publication in: Movement Disorders (the "Journal")

Published by Wiley on behalf of The International Parkinson and Movement Disorder Society (the "Owner")

Dear Contributor(s):

Thank you for submitting your Contribution for publication. In order to expedite the editing and publishing process and enable the Owner to disseminate your Contribution to the fullest extent, we need to have this Copyright Transfer Agreement executed. If the Contribution is not accepted for publication, or if the Contribution is subsequently rejected, this Agreement shall be null and void. Publication cannot proceed without a signed copy of this Agreement.

\section{A. COPYRIGHT}

The Contributor assigns to the Owner, during the full term of copyright and any extensions or renewals, all copyright in and to the Contribution, and all rights therein, including but not limited to the right to reproduce, publish, republish, transmit, sell, transfer, distribute, and otherwise use the Contribution in whole or in part in electronic and print editions of the Journal and in derivative works throughout the world, in all languages and in all media of expression now known or later developed, and to license or permit others to do so.

\section{B. RETAINED RIGHTS}

Notwithstanding the above, the Contributor or, if applicable, the Contributor's employer, retains all proprietary rights other than copyright, such as patent rights, in any process, procedure or article of manufacture described in the Contribution. This reservation of rights does not affect or limit the rights assigned to Owner in Section A.

\section{PERMITTED USES BY CONTRIBUTOR}

1. License. The Owner grants to Contributor a non-exclusive, non-transferable and limited license to reproduce and distribute copies of the print or electronic "preprints" of the unpublished Contribution, in the original form submitted to the Journal prior to the peer review process, solely to colleagues within the Contributor's nonprofit organization or educational institution. The Contributor shall make no more than 100 printed copies of the preprints in any calendar year. Such preprints may be posted as electronic files on the Contributor's own personal website, on the Contributor's internal intranet at Contributor's nonprofit organization or educational institution, or on a secure external website at the Contributor's nonprofit organization or educational institution, provided that access is limited to employees and/or students at Contributor's non-profit organization or educational institution. Contributor shall not charge a fee for any 
preprints, and Contributor's use under this Section C shall not be for any commercial purpose, or for any systematic external distribution (e.g., posting on a listserve, public website, database connected to a public access server, or automated delivery system). The license grant in this Section does not apply to for-profit corporations, and any proposed use outside of the scope of this Section C must be pre-approved in writing by the Owner. The rights granted to Contributor under this Section $\mathrm{C}$ do not include reproduction, distribution or any other use of rating scales, videos or other audiovisual materials associated with the Contribution.

2. Required Citation. Prior to publication, the Contributor must provide full credit and acknowledgement of the Journal in all preprints in the following format: This is a preprint of an article accepted for publication in [Journal Title], Copyright ( [year] The International Parkinson and Movement Disorder Society. After publication, the Contributor must provide a citation to the Journal in all preprints in the following format: This is a preprint of an article that was published in [Journal title]: (Title of Article, Contributor, Journal Title and Volume/ Issue, Copyright $($ ) [year] The International Parkinson and Movement Disorder Society). An electronic link must be provided to the Journal's website, located at http://www.interscience.Wiley.com. The Contributor agrees not to update the preprint or replace it with the published version of the Contribution.

3. Accepted Version. Re-use of the accepted and peer-reviewed (but not the final typeset published) version of the Contribution (the "Accepted Version") is not permitted under this Agreement. There are separate arrangements with certain funding agencies governing reuse of the Accepted Version. Additional terms apply if the Contributor receives or received funding from these agencies. The details of those relationships, and other offerings allowing open web use, are set forth at the following website: http://www.wiley.com/go/ funderstatement.

4. Additional Terms for Certain Funders. Certain funders, including the NIH, members of the Research Councils UK (RCUK) and Wellcome Trust require deposit of the Accepted Version in a public repository after an embargo period. Details of funding arrangements are set out at the following website:

http://www.wiley.com/go/funderstatement. Additional terms may be applicable. Please contact the production editor for the journal at MDSprod@wiley.com if you have additional funding requirements.

If any Contributor receiving funds from applicable sources does not choose the Owner's OnlineOpen option, the Contributor will be allowed to self-archive by depositing the Accepted Version in a public repository after the following applicable embargo period has expired, subject to further conditions imposed by the RCUK:

a. $\quad 12$ months from first publication online of the final published version of the Contribution for research funded by members of the Research Councils UK (RCUK) other than The Economic and Social Research Council (ESRC) and the Arts and Humanities Research Council (AHRC); or

b. $\quad 24$ months from first publication online of the final published version of the Contribution for research funded by ESRC or AHRC.

5. Additional Terms for Certain Institutions. Wiley has arrangements with certain educational institutions to permit the deposit of the Accepted Version in the institutional repository after an embargo period. Details of such arrangements are set out at the following website: http://olabout.wiley.com/WileyCDA/Section/id-406074.html . Additional terms may be applicable.

If any Contributor affiliated with these applicable educational institutions does not choose the Owner's OnlineOpen option, the Contributor will be allowed to self-archive by depositing the Accepted Version in the educational institution's repository after the following applicable embargo period has expired. See the following website for details: http://olabout.wiley.com/WileyCDA/Section/id-817011.html. 


\section{CONTRIBUTIONS OWNED BY EMPLOYER}

If the Contribution was written by the Contributor in the course of the Contributor's employment (as a "work-made-for-hire" in the course of employment), the Contribution is owned by the company/institution which must execute this Agreement (in addition to the Contributor's signature). In such case, the company/institution hereby assigns to the Owner, during the full term of copyright, all copyright in and to the Contribution for the full term of copyright throughout the world as specified in Section A above.

\section{E. GOVERNMENT CONTRACTS}

In the case of a Contribution prepared under U.S. Government contract or grant, the U.S. Government may reproduce, without charge, all or portions of the Contribution and may authorize others to do so, for official U.S. Government purposes only, if the U.S. Government contract or grant so requires. (U.S. Government, U.K. Government, and other government employees: see notes at end.)

\section{F. CONTRIBUTOR'S REPRESENTATIONS}

The Contributor represents that the Contribution is the Contributor's original work, all individuals identified as Contributors actually contributed to the Contribution, and all individuals who contributed are included. The Contribution is submitted only to this Journal and has not been published before. (If excerpts from copyrighted works owned by third parties are included, the Contributor will obtain written permission from the copyright owners for all uses as set forth in the Journal's Instructions for Contributors, and show credit to the sources in the Contribution.) The Contributor also warrants that the Contribution contains no libelous or unlawful statements, does not infringe upon the rights (including without limitation the copyright, patent or trademark rights) or the privacy of others, or contain material or instructions that might cause harm or injury. Upon request, Contributor will provide the data or will cooperating fully in obtaining and providing the data on which the Contribution is based for examination by the editors or their assignees.

\section{G. FINANCIAL DISCLOSURES}

The Contributor certifies that his/her financial and material support for this research and work, regardless of date, is clearly identified on Exhibit A to this Agreement. The Contributor has also identified on Exhibit A, all other support unrelated to this research, covering the past year from the date of submission (e.g., grants, advisory boards, employment, consultancies, contracts, honoraria, royalties, expert testimony, partnerships, or stock ownership in medically-related fields).

\section{H. VIDEO AND PHOTOGRAPHY CONSENT}

In the event that the Contribution includes, discloses or incorporates any content (including, without limitation, any video clip or photograph) which identifies any individual patient(s) ("patient identifiable content"), the Contributor obtained from such patient(s) written consent to such inclusion, disclosure or incorporation and that this consent fully complies with all legal requirements, including without limitation, all of the requirements of the laws of the jurisdiction(s) to which the patient(s) and the patient(s)' physician are subject, including the United States Health Insurance Portability and Accountability Act of 1996 ("HIPAA") if applicable. The Contributor hereby certifies that, if the patient consent form is in a language other than English, such consent form meets all of the requirements set forth in the Instructions to Authors. In addition, the Contributor hereby confirms that he/she obtained from patient(s) written consent to use the patient identifiable content in both print and online (i.e., internet/web-based) publication formats. The Contributor further certifies that the person executing any such patient consent form, to the best of his/her knowledge, had legal capacity under applicable law to execute the form on behalf of the patient. 


\section{ACKNOWLEDGEMENTS}

The Contributor should obtain written permission from all individuals named in the acknowledgement since readers may infer their endorsement of data and conclusions. The Contributor certifies that all individuals named in the acknowledgement section have provided written permission to be named.

\section{J. MISCELLANEOUS}

This Agreement may be amended or modified only in a writing executed by both parties. The waiver or failure of any party to exercise any rights under this Agreement shall not be deemed a waiver or other limitation of any other right or any future right. This Agreement shall inure to the benefit of, and shall be binding upon, the parties, their respective successors and permitted assigns. This Agreement may be executed in two (2) or more counterparts, each of which shall be an original and all of which taken together shall constitute one and the same agreement. Executed copies of this Agreement may be delivered by facsimile transmission, pdf/email or other comparable electronic means. If for any reason any provision of this Agreement shall be deemed by a court of competent jurisdiction to be legally invalid or unenforceable, the validity, legality and enforceability of the remainder of this Agreement shall not be affected and such provision shall be deemed modified to the minimum extent necessary to make such provision consistent with applicable law and, in its modified form, such provision shall then be enforceable and enforced. The parties agree to do such further acts and to execute and deliver such additional agreements and instruments from time to time as either may at any time reasonably request in order to assure and confirm unto such requesting party the rights, powers and remedies conferred in the Agreement. This Agreement, including any exhibits attached hereto, contains the entire agreement and understanding of the parties with respect to the subject matter hereof, and supersedes all prior agreements, negotiations, representations and proposals, written and oral, relating thereto.

\section{All Contributors must sign below. Contributors must check one box except that NIH grantees should check both Contributor-owned work and the NIH grantee box. If your Contribution was written during the course of employment, your employer must also sign where indicated.}

Please send your original completed and signed forms by fax or email a scanned copy to the Journal production editor. For production editor contact details please visit the Journal's online author guidelines. Do not send in hard copies of these forms.

[ $]$ Contributor-owned work

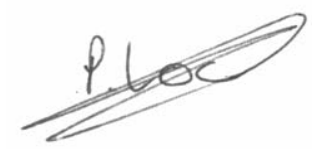

Contributor's signature

$11-11-2019$

Date

Dr Paul Lockhart (Associate Professor)

Type or print name and title

Co-Contributor's signature

Date

Type or print name and title 
[__ Company/Institution-owned

Work (made-for-hire in the

Company or Institution (Employer-for-Hire)

Date

Course of employment)

Authorized signature of Employer

Date

Contributor's signature

Date

Type or print name and title

\section{ATTACH ADDITIONAL SIGNATURE PAGES AS NECESSARY}

\section{[ ] U.S. Government work}

Note to U.S. Government Employees

A contribution prepared by a U.S. federal government employee as part of the employee's official duties, or which is an official U.S. Government publication, is called a "U.S. Government work", and is in the public domain in the United States. In such case, Paragraph A.1 will not apply but the Contributor must type his/her name (in the Contributor's signature line) above. Contributor acknowledges that the Contribution will be published in the United States and other countries. If the Contribution was not prepared as part of the employee's duties or is not an official U.S. Government publication, it is not a U.S. Government work.

\section{[ ] U.K. Government work (Crown Copyright)}

Note to U.K. Government Employees

The rights in a contribution prepared by an employee of a UK government department, agency or other Crown body as part of his/her official duties, or which is an official government publication, belong to the Crown. Contributors must ensure they comply with departmental regulations and submit the appropriate authorisation to publish. If your status as a government employee legally prevents you from signing this Agreement, please contact the Journal production editor.

\section{[ ] Other}

Including Other Government work or Non-Governmental Organisation work Note to Non-U.S., Non-U.K. Government Employees or Non-Governmental Organisation Employees If your status as a government or non-governmental organisation employee legally prevents you from signing this Agreement, please contact the Journal production editor. 


\section{Exhibit A}

\section{Financial Disclosure}

The Contributor has received financial and material support for this research and work regardless of date from the following sources:

Name: Paul Lockhart

Address: MCRI, 50 Flemington Rd, Parkville, Australia, 3052

Type of support: Grant funding

This material will be printed with the published article.

This work was funded in part by grants to Paul Lockhart from the McCusker Charitable Foundation, National Health \& Medical Research Council (Australia) project grants (GNT1041860, GNT1144724) and the Michael J Fox Foundation/Shake It Up Grant (12173).

In the past year from the date of submission, the Contributor has also received the following support unrelated to this research (e.g., grants, advisory boards, employment, consultancies, contracts, honoraria, royalties, expert testimony, partnerships, or stock ownership in medically-related fields):

Paul Lockhart has received the following unrelated support: NHMRC Australia, GNT1128933, Tuberous sclerosis and epilepsy: using resected tissue to understand pathogenesis and inform management (2017-2018); NHMRC Australia, GNT1098255, Understanding the Neurobiology of Autism Spectrum Disorder (2016-2020); NHMRC Australia, GNT102207, A randomized placebo-controlled crossover trial of micronized resveratrol as a treatment for Friedreich ataxia (2016-2018); Vincent Chiodo Foundation. 


\section{University Library}

\section{- M M N E R VA A gateway to Melbourne's research publications}

Minerva Access is the Institutional Repository of The University of Melbourne

Author/s:

Gao, Y;Martinez-Cerdeno, V;Hogan, KJ;McLean, CA;Lockhart, PJ

Title:

Clinical and Neuropathological Features Associated With Loss of RAB39B

Date:

2020-01-17

Citation:

Gao, Y., Martinez-Cerdeno, V., Hogan, K. J., McLean, C. A. \& Lockhart, P. J. (2020).

Clinical and Neuropathological Features Associated With Loss of RAB39B. MOVEMENT DISORDERS, 35 (4), pp.687-693. https://doi.org/10.1002/mds.27951.

Persistent Link:

http://hdl.handle.net/11343/275270 